\title{
Un primer congreso reflexiona sobre la evolución y logros de la arqueología náutica y subacuática española
}

\begin{abstract}
Del 14 al 16 de marzo de 2013 se celebró en el Museo Nacional de Arqueología Subacuática (ARQUA) el I Congreso de Arqueología Náutica y Subacuática Española en que se inscribieron 298 personas, presentándose 83 comunicaciones y 31 pósteres. El congreso se presentaba como una ocasión para hacer visible la evolución y logros de la arqueología subacuática española, así como para facilitar una reflexión sobre el proceso seguido contribuyendo a normalizar esta actividad. Invitamos a Xavier Nieto, director de ARQUA y miembro de la comisión científica del congreso, a que reseñara dicho evento.
\end{abstract}

Xavier Nieto Prieto | director del Museo Nacional de Arqueología Subacuática (ARQUA)

URL de la contribución <www.iaph.es/revistaph/index.php/revistaph/article/view/3404>

Puede sorprender el elevado número de comunicaciones presentadas (83, más unas 20 que fueron rechazadas por el comité científico, mayoritariamente por la falta de tiempo para su exposición durante dos días y medio). En total unas 130 comunicaciones y pósteres que trataron sobre otras tantas actuaciones realizadas sobre el patrimonio cultural subacuático español. Éste era uno de los objetivos del congreso: mostrar el dinamismo de esta actividad, aspecto que quedó todavía más reforzado con los casi 300 participantes inscritos.

La arqueología náutica y en especial la subacuática son, en nuestro país, unas actividades todavía no plenamente normalizadas y en buena parte desconocidas, tanto para el gran público como para las instituciones e incluso para la comunidad científica. El congreso pretendió contribuir a hacerlas visibles y a fortalecer los vínculos entre los actores, con el convencimiento de que ello colaboraría, en última instancia, a crear un estado de opinión favorable hacia la necesidad de conservar el patrimonio cultural subacuático, todavía muy amenazado, y a crear una masa crítica que asegure el futuro y la calidad de los trabajos que se realicen.

El momento cronológico era el adecuado. Durante las últimas décadas la arqueología subacuática española ha experimentado un desarrollo espectacular que se hace patente tanto en el número de profesionales existentes (baste recordar que a los inicios de los años 80 del siglo pasado no existía en España ningún arqueólogo subacuático titulado y hoy puede realizarse este congreso), como en los cambios legislativos (entrada en vigor en el año 2009 de la Convención 2001 de la UNESCO para la protección del patrimonio cultural subacuático, ratificada por España en el año 2005), como por la creación de los centros autonómicos y el nacional especializados en esta materia, todo lo cual ha generado un nuevo modelo de gestión de este patrimonio. Era conveniente reunir a los actores más directos y hacer balance.

Era también el momento propicio porque el asunto Odyssey y el "tesoro" de la fragata Nuestra Señora de las Mercedes era y es de enorme actualidad en todos los medios de comunicación y no han faltado voces privadas e incluso grupos de presión poderosos que han defendido la venta de este patrimonio cultural como parte de la solución a todos los males que afectan a la economía de nuestro país. Incluso han defendido la concesión de autorizaciones a empresas extranjeras ante la falta de técnicos y medios en nuestro país para llevar a cabo trabajos arqueológicos subacuáticos. Hacer patentes más de 130 actuaciones arqueológicas subacuáticas, de alto nivel científico y con una inequívoca finalidad patrimonial, proporciona un argumento de peso, del que quedará constancia permanente en el momento en que se publiquen las actas de este congreso.

Sin duda a la arqueología náutica y subacuática española le queda un largo camino por recorrer hasta su normalización, pero se ha dado un paso más para poner a disposición de la sociedad los documentos que permitan el conocimiento científico de una herencia cultural que le pertenece. 